
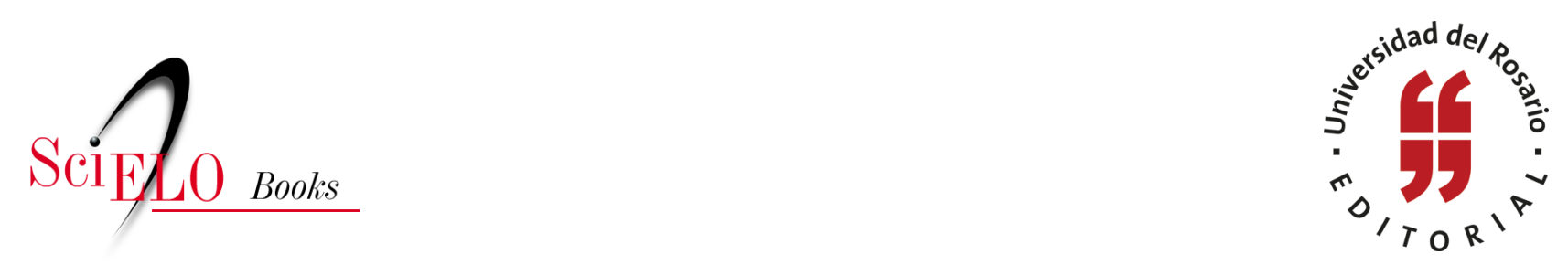

\title{
Principios fundantes del estado social de derecho en relación con los adultos mayores privados de la libertad
}

\author{
Carol Iván Abaunza Forero \\ Mónica Alexandra Mendoza Molina \\ Paola Bustos Benítez \\ Giovanny Paredes Álvarez \\ Karla Vanessa Enriquez Wilches \\ Andrea Carolina Padilla Muñoz
}

\section{SciELO Books / SciELO Livros / SciELO Libros}

ABAUNZA FORERO, C.I., MENDOZA MOLINA, M.A., BUSTOS BENÍTEZ, P., PAREDES ÁLVAREZ, G., ENRIQUEZ WILCHES, K.V., and PADILHA MUÑOZ, A.C. Principios fundantes del estado social de derecho en relación con los adultos mayores privados de la libertad. In: Adultos mayores privados de la libertad en Colombia [online]. Bogotá: Editorial Universidad del Rosario, Instituto Rosarista de Acción Social - SERES, 2014, pp. 26-32. ISBN 978-958-738-532-8.

https://doi.org/10.7476/9789587385328.0003.

All the contents of this work, except where otherwise noted, is licensed under a Creative Commons Attribution 4.0 International license.

Todo o conteúdo deste trabalho, exceto quando houver ressalva, é publicado sob a licença Creative Commons Atribição $\underline{4.0}$.

Todo el contenido de esta obra, excepto donde se indique lo contrario, está bajo licencia de la licencia Creative Commons $\underline{\text { Reconocimento 4.0. }}$. 


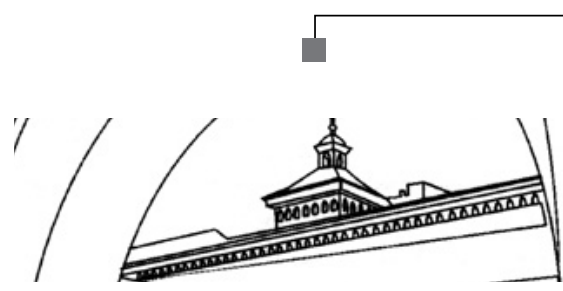




\section{Principios fundantes del estado social de derecho en relación con los adultos mayores privados de la libertad}




\section{Principios de solidaridad y dignidad}

La solidaridad es un principio que se debe garantizar a la población carcelaria; se considera como "el reconocimiento práctico de la obligación natural que tienen los individuos y los grupos humanos de contribuir al bienestar de los que tienen que ver con ellos, especialmente de los que tienen mayor necesidad" (Sebastián, 2000, p. 11), o también se entiende "como la oportunidad que tiene un individuo de colaborar con el bienestar de sus congéneres, en especial de los que se encuentran necesitados de ayuda o en situación apremiante, gracias a lo cual la persona solidaria engrandece su dignidad humana y contribuye a respetar los derechos de quien ha acudido en su ayuda o necesitado de su auxilio" (Sebastián, 2000, p. 11).

De hecho, resulta patente que la fraternidad se debe interpretar a partir de la solidaridad; la doctrina ha considerado que es una cualidad inherente en el ser humano y la sociedad como tal. Se ha afirmado que el ser humano no puede escapar de la solidaridad en el momento de auxiliar a un tercero en necesidad: "La fraternidad también sigue siendo un concepto vigente; un concepto de importancia fundamental en un mundo que ha atravesado por tan tremendas luchas internacionales e internas. [...] Es un hecho real que existe la solidaridad entre los hombres para el bien y para el mal" (Rawls, s. f., p. 138).

La solidaridad puede surgir de una necesidad personal o colectiva, en aras de preservar la salubridad pública o la propia. Además, es relevante hacer mención en el hecho de que el mundo se ha urbanizado y, por lo tanto, tenemos que convivir en una sociedad solidaria, fundada en el interés común.

De lo anterior existen varios ejemplos dentro de los ámbitos tanto jurídico como de propiedad, que por esencia tienen una función social que se antepone al interés particular; así las cosas, la propiedad debe ceder al interés público siempre que sea necesario, restringiendo de este modo el derecho a la propiedad privada.

Cede al interés público, cuando este se encuentre en conflicto con el particular; por lo tanto, en desarrollo de la función social y ecológica, se 
pueden decretar expropiaciones por motivos de utilidad pública o interés social, mediante sentencia judicial, indemnización previa y por motivos expresamente señalados por el legislador. (Corte Constitucional, 2002)

De igual forma y a escala internacional, esto se repite, nadie puede vivir aislado, y si se es parte de una sociedad, debe haber una solidaridad mínima para que la convivencia pueda ser garantizada. Rawls (s. f.) menciona que si la especie humana es solidaria, esta debe brindar un trato fraternal a los demás, siempre desde un punto de vista de colaboración y acercamiento, ya que "las medidas que se desprenden del hecho de la solidaridad no deben ser egoístas, frías, sino que tienen que estar alimentadas por el calor humano, por el amor a los semejantes" (Rawls, s. f., p. 138).

El principio de solidaridad es fundante en nuestro ordenamiento jurídico; está consagrado en la Carta Política, y ha sido tratado en copiosa jurisprudencia a lo largo de los años. Al respecto, Escamilla afirma que el concepto de solidaridad ha sufrido mucho para poder ser tenido en cuenta como fundamental; desde un punto de vista sociológico y normativo, este deber ser fue incluido en la Carta Política de 1991 y "de igual forma, su presencia se tiene como fundamento de diversas instituciones jurídicas" (Escamilla, 2004, p. 606).

Desde la esfera del ámbito penal, podemos ver que el principio de solidaridad está presente cuando se castiga la conducta de omisión, como una clara manifestación contraria a este principio. Esta relevancia quedó registrada en la exposición de motivos del Código Penal (CP) de 2000, dada su importancia y trascendencia (Escamilla, 2004). Escamilla también indica que la relación entre el deber de solidaridad y los delitos de omisión es, por supuesto, coherente, ya que solo se puede incurrir en una conducta punible de este tipo - omisión - cuando se tiene un deber jurídico de actuar, y esa infracción está estipulada expresamente en la normatividad.

También se puede observar que la solidaridad está presente en otras ramas del derecho en que las personas deben asumir una carga que las afecta económicamente; deben realizar, periódicamente, un pago en beneficio de la sociedad, los comúnmente llamados impuestos. Por otro lado, y análogo al aspecto carcelario, no se puede pasar por alto el importante rol que 
tienen los abogados defensores de oficio en los procesos penales; al respecto, la Corte Constitucional ha mencionado que ese tipo de profesionales del derecho contribuyen, de manera directa, con el desarrollo del principio de solidaridad en nuestra sociedad, al ser designados sin contraprestación económica alguna.

La Organización de las Naciones Unidas (ONU) también se ha referido a la solidaridad, que, de hecho, se deriva en muchos casos de la dignidad para el AM. Cuando existe solidaridad, la dignidad de las personas que han entrado a la vejez puede ser garantizada y, por esta razón, la ONU la declara como un principio básico, mediante la Resolución 46/91, a partir de la cual se establecen los principios de las Naciones Unidas en favor de las personas de edad (ONU, 1991). Por lo tanto, se le debe garantizar al AM una protección especial en aras de la garantía de sus derechos, a partir de la consideración de su condición de vulnerabilidad.

Tanto es así que se ha desarrollado un claro precedente jurisprudencial en el que se protegen los derechos de las personas que se encuentran en la vejez y que, posiblemente, están inmersas en un estado de debilidad manifiesta que atenta especialmente contra el derecho a la vida digna y otros derechos conexos, para que sean protegidas a través del mecanismo de la acción de tutela, así existan otras acciones judiciales disímiles a las que pueden acudir.

Que existiendo fundamento fáctico para otorgar el amparo, si el medio de defensa judicial común no es eficaz, idóneo o expedito para lograr la protección y esta llegaría tarde, encontrándose la persona en una circunstancia de debilidad manifiesta, o en insubsanable apremio en su mínimo vital, la tutela puede tener procedencia. (Corte Constitucional, 2011)

El concepto de debilidad manifiesta cobra una especial importancia en el momento de evaluar si una acción jurídica puede no ser lo suficientemente célere para proteger los intereses de los AM y, por esta razón, el papel de la tutela cobra tal importancia. La condición de debilidad mani- 
fiesta suele ser inherente en el AM; sin embargo, dicha situación se puede agravar en un escenario adverso donde difícilmente pueda ser garantizado un ambiente digno, como la cárcel. Por eso, el derecho penal consagra que la dignidad humana es sustantiva, sobre todo para las PPL (Código Penal).

El Estado tiene deberes especiales para con los reclusos, con miras a que estos puedan ejercer plenamente los derechos fundamentales que no les han sido suspendidos, y parcialmente aquellos que les han sido restringidos. Y estos deberes no implican simplemente que el Estado no debe interferir en la esfera de desarrollo de estos derechos - como ocurriría en el caso de la libertad religiosa-, sino también -y de manera especial- que el Estado debe ponerse en acción para garantizarle a los internos el pleno goce de otros derechos, tales como la dignidad, la salud, la alimentación, el trabajo, etc. Esta conclusión se deriva de la misma relación especial de sujeción de los penados frente al Estado, y del hecho de que las condiciones que se imponen a los reclusos les impide que puedan satisfacer por cuenta propia una serie de necesidades mínimas, cuya atención garantiza la posibilidad de llevar una vida digna. (Corte Constitucional, 1998)

El Estado, frente a las PPL en los EPC, tiene la obligación de respetar y velar por la dignidad humana, y por esta razón deberá siempre de abstenerse de obligar a un detenido a soportar una carga que no esté en la obligación de sobrellevar, o a darle un trato desigual que atente contra su dignidad: "Es deber del Estado tratar a los presos justamente y respetar su dignidad humana, por lo que debe resguardarse de ponerlos en condiciones de desigualdad entre sí. Garantizar los derechos del privado de libertad colabora con su reintegración a la sociedad una vez cumplida la condena" (Castro et al., 2010, p. 19). El Estado ostenta una obligación de resultado, máxime cuando se trata de un AM, quien debe ser protegido de manera especial; debe tratar de manera semejante a los iguales y de forma desigual a los que se encuentran en situaciones disímiles, como es el caso de una persona de la tercera edad en comparación con el resto de la población carcelaria. 
La Sala ha reiterado que frente a los retenidos la obligación que tiene el Estado de respetar y garantizar su vida e integridad personal y síquica es de resultado. El Estado asume una obligación específica de protección y seguridad, en virtud de la cual se hace responsable de los perjuicios que sufren las personas. Es el caso de los retenidos, quienes por encontrarse en una situación de particular sujeción frente al Estado en virtud de la cual ven limitados sus derechos y libertades y la autonomía para responder por su propia integridad, deben gozar del pleno amparo de las autoridades frente a los posibles daños y peligros que los amenacen. (Consejo de Estado, 1998)

En el momento en que una PPL sufra un perjuicio derivado de un daño en concreto, sobre todo cuando se trata de una persona que se encuentra en estado de debilidad manifiesta y que, por lo tanto, debe recibir una protección especial, se configura de manera aún más clara una falla en el servicio. Cuando esto se presenta, el Estado puede estar sujeto a una responsabilidad civil extracontractual, tratándose tanto de la PPL como de su familia cercana. Y es que un perjuicio contra la dignidad humana de cualquier PPL conlleva una serie de daños que deben ser resarcidos mediante una compensación monetaria a cargo del Estado, el cual no fue diligente en su accionar e incumplió con las obligaciones constitucionales que le eran atribuibles:

De acuerdo con la jurisprudencia vigente, el título de responsabilidad en los casos en los que se pretende imputar daños al Estado por la muerte o las lesiones sufridas por quienes se encuentran privados de la libertad en calidad de sindicados o condenados en los establecimientos carcelarios, corresponde al de la falla del servicio, esto es, por el incumplimiento o el cumplimiento defectuoso o tardío del servicio carcelario. (Sentencia Consejo de Estado, 2008). 